\title{
Produtividade e acúmulo de nutrientes em plantas de jambu, sob adubação orgânica e mineral
}

\section{Productivity and accumulation of nutrients in plants of jambu, under mineral and organic fertilization}

\author{
Luciana da Silva Borges $^{1 *}$; Amaralina Celoto Guerrero ${ }^{1}$; \\ Rumy Goto ${ }^{2}$; Giuseppina Pace Pereira Lima ${ }^{3}$
}

\section{Resumo}

\begin{abstract}
A produção orgânica é um sistema que permite alcançar bons níveis de produtividade, evitando ao mesmo tempo os riscos de contaminação química do agricultor, dos consumidores e do meio ambiente. Pelo fato da planta de jambu ser bastante utilizada como medicamento alternativo e por indústrias de cosméticos, vem aumentando o interesse pelo seu cultivo. Assim, o objetivo desse trabalho foi analisar a biomassa, acúmulo de nutrientes, a produtividade e determinar o resíduo de agrotóxico em plantas de jambu quando cultivado sob adubação orgânica e mineral. O experimento foi conduzido na Fazenda Experimental São Manuel, FCA/UNESP. O delineamento estatístico foi em blocos casualizados, com esquema fatorial $(2 \times 6)$, sendo duas fontes de adubação (orgânica e mineral) e seis doses de nitrogênio, com quatro repetições. As características avaliadas foram alturas de plantas, massas frescas e secas de folhas, produtividade e acúmulo de nutrientes. A adubação mineral proporcionou maior biomassa, produtividade e acúmulo de $\mathrm{N}, \mathrm{P}$ e $\mathrm{K}$ em relação à adubação orgânica utilizada. Preconiza-se a dose de $90 \mathrm{~g} \mathrm{~m}^{-2}$ de uréia como adequada para obtenção desses resultados. Com tudo a adubação orgânica favoreceu ao acúmulo de $\mathrm{P}$ nas plantas de jambu em relação à adubação mineral, sendo a dose de 10 $\mathrm{kg} \mathrm{m}^{-2}$ de esterco de curral recomendada para conseguir esse resultado nas plantas de jambu. Não foi detectada a presença de agrotóxicos fosforados e carbamatos em folhas de plantas jambu sob adubação orgânica e mineral. No entanto, foi observada a presença de clorados nas folhas nas duas adubações utilizada.
\end{abstract}

Palavras-chave: Spilanthes oleracea, resíduo de agrotóxico, nutrição de plantas, fertilizantes químico e orgânico

\begin{abstract}
The organic production is a system that allows achieving good levels of productivity, while avoiding the risks of chemical contamination of farmers, consumers and the environment. Because jambu plant is widely used as alternative medicine and cosmetics industries, has been increasing interest in its cultivation. The aim of this study was to analyze the biomass, accumulation of nutrient, productivity and determine the pesticide residue in plant jambu when grown under organic and mineral fertilization. The experiment was conducted at the Experimental Farm São Manuel, FCA / UNESP. The experiment was conducted at São Manuel Experimental Farm UNESP. The statistical was arranged in the randomized block design, in a 2 x 6 factorial scheme, two sources of fertilizers (organic and mineral) and six doses of nitrogen, with four replications. The characteristics evaluated were plant height, fresh and dry
\end{abstract}

${ }_{1}$ Discente(s) de Doutorado em Agronomia/Horticultura. Dept ${ }^{0}$ de Produção Vegetal, Setor Horticultura, UNESP, Botucatu, SP. E-mail: luagro06@yahoo.com.br; amaralina@fca.unesp.br

2 Prof $^{a}$. Dept ${ }^{\circ}$ de Produção Vegetal, Setor Horticultura, UNESP, Botucatu, SP. E-mail: rumy@fca.unesp.br

${ }^{3}$ Prof $^{a}$. Dept ${ }^{\circ}$ de Química e Bioquímica, Instituto de Biociências, UNESP, Botucatu, SP. E-mail: gpplima@ibb.unesp.br

* Autor para correspondência 
weight, nutrients of accumulation in shoots and productivity. Mineral fertilizer gave higher biomass, productivity and accumulation of $\mathrm{N}$ and $\mathrm{K}$ in relation to organic fertilizer used. It is recommended the dose of $90 \mathrm{~g} \mathrm{~m}^{-2}$ of urea as appropriate to obtain these results. However the organic fertilization favored the accumulation of phosphorus in plants jambu in relation the mineral fertilizer, and the dose of $10 \mathrm{~kg}$ $\mathrm{m}^{-2}$ of cattle manure recommended to achieve this result in plants jambu. We did not detect the presence of phosphorous and carbamate on leaves of jambu under organic and mineral fertilization. However, we observed the presence of chlorine in the leaves used for the two fertilizations.

Key words: Spilanthes oleracea, pesticide of residue, plant nutrition, chemical and organic fertilization

\section{Introdução}

O jambu (Spilanthes oleracea), pertence à família Asteraceae, nativa da Amazônia, de clima tropical (VILLACHICA et al., 1996). A planta de jambu atinge cerca de $40 \mathrm{~cm}$ de altura e é uma planta C3, herbácea, ramificada e semi-carnosa (ALBURQUERQUE, 1989). A raiz é axial com muitas ramificações, a haste é do tipo rastejante ramificada em dicásio, podendo ocorrer em tricásio. As flores são em capítulos globosos, amarelados e longo pedunculados. Sua propagação pode ser por semente ou estaquia (CARDOSO; GARCIA, 1997).

Essa planta é uma hortaliça bastante cultivada e consumida na região Norte do Brasil, principalmente no Pará, sendo sua maior demanda nos períodos festivos, tais como o Círio de Nazaré e as festas de fim de ano. Popularmente essa planta também é utilizada como erva medicinal, pois segundo os dizeres populares suas folhas e flores podem ser recomendadas para elaboração de infusões no tratamento de anemia, dor de dente e garganta, sendo sugerido como antibiótico e anestésico.

Nos primeiros estudos fitoquímicos Spilanthes oleracea, Jacobson (1957) descreveu o "espilantol" como uma amida ( $\mathrm{N}$-isobutilamidas), ocorrendo também em outras espécies do gênero Spilanthes. Resultados semelhantes foram descritos por Ramsewak, Erickson e Nair (1999). As flores e as folhas de Spilanthes acmella contêm aminoácidos, alcalóides (PEIRIS; SILVA; RATNASOORIYA, 2001) e possui em torno de $0,7 \%$ de óleo essencial, além de flavonóides (LORENZI; MATOS, 2002).

Por apresentar essas propriedades químicas, essa planta vem despertando o interesse das empresas farmacêuticas e de cosméticos que utilizam as plantas como matéria prima para seus produtos, e têm optado por plantas cultivadas de forma orgânica, uma vez que esses produtos estarão isentos dos resíduos químicos dos defensivos, sem deixar de ressaltar a questão da conservação do meio ambiente.

A produção orgânica de hortaliça no mundo, principalmente na Região Sudeste do Brasil vem crescendo, sendo uma ótima alternativa para os pequenos agricultores, já que utiliza menor quantidade de insumos agrícolas e apresentam alto valor agregado, devido à preferência dos consumidores por alimentos mais saudáveis (CAMPANHOLA; VALARINI, 2001).

Dentre as vantagens decorrentes do uso de adubos orgânicos, destaca-se o fornecimento de nutrientes de acordo com a exigência da planta, especialmente $\mathrm{N}, \mathrm{P}, \mathrm{S}$ e micronutrientes, sendo a única forma de armazenamento de $\mathrm{N}$ que não volatiliza. Responsável por $80 \%$ do $\mathrm{P}$ total encontrado no solo, é uma fonte de nutrientes mais completa e equilibrada para as plantas do que os adubos minerais, sem haver grandes perdas por lixiviação (CARDOSO; OLIVEIRA, 2004).

Das fontes de matéria orgânica, o esterco bovino ou de curral, é considerado um dos poucos com maior potencial como fertilizante. É o subproduto da excreção de bovinos, que exerce importância para a agricultura, uma vez que quando devidamente mineralizado melhora as condições físicas, químicas e biológicas do solo. Sua utilização como adubo, vem se observando desde a antigüidade com a finalidade de melhorar a estruturação do solo (PRAXEDES, 2000). 
As hortaliças se diferenciam nas exigências nutricionais e no padrão de absorção durante o crescimento. Em geral, a absorção de nitrogênio, fósforo e potássio segue a mesma tendência que a taxa de acúmulo de biomassa da cultura. As hortaliças folhosas apresentam lenta absorção de nutrientes durante a primeira metade do ciclo de cultivo, sendo que o índice de absorção de nutrientes acelera-se próximo à colheita (PAPADOPOULOS, 1999).

Dentre os nutrientes mais absorvidos pelas plantas, o nitrogênio e o fósforo possuem forte papel estrutural fazendo parte dos nucleotídeos, os quais formam os ácidos nucléicos (DNA e RNA). Além disso, o nitrogênio está presente nos aminoácidos que formam as proteínas e na própria molécula de clorofila. O potássio apesar de ser um macronutriente não é um componente estrutural, contudo ele está presente em altas concentrações no suco celular regulando o potencial osmótico e o balanço iônico e no controle do movimento estomático (SANTOS, 2004).

Embora o uso de agrotóxicos traga benefícios no aumento da produção agrícola, sua toxicidade deve ser considerada, e para isso torna-se necessário controlar a qualidade dos produtos hortícolas, para evitar possíveis riscos para os consumidores (FENOLL, et al., 2007). Dentre os agrotóxicos, destacam-se os organoclorados, organofosforados, carbamatos, que aparecem devido à aplicação de substâncias tais como fertilizantes, inseticidas, entre outros, durante o cultivo, transporte ou armazenamento (RITTER, 1997; JEYARATNAM, 1994). Alguns resíduos de agrotóxicos podem ser encontrados nos alimentos cultivados de forma mineral e orgânica, sendo nesta última, devido principalmente à contaminação da água e solo. Segundo Gobo et al. (2004), a análise de resíduos de agrotóxicos é de grande importância, porque permite determinar se estes resíduos encontramse dentro de um nível de tolerância estabelecido. Pesquisas sobre o manejo, adubação adequada, acúmulo de nutrientes e resíduos de agrotóxicos em plantas de jambu são ainda incipientes em todo território brasileiro. Este trabalho teve como objetivo analisar a biomassa, acúmulo de nutrientes, produtividade e resíduos de agrotóxicos em folhas de plantas de jambu quando cultivado sob adubação orgânica e mineral.

\section{Material e Métodos}

O experimento foi conduzido na Fazenda Experimental São Manuel (São Manuel-SP), com coordenadas geográficas aproximadas de latitude $22^{\circ} 44^{\prime} 50^{\prime \prime}$ Sul e longitude $48^{\circ} 34{ }^{\circ} 00^{\prime}$ 'Oeste de Greenwich, com altitude em torno de $765 \mathrm{~m}$.

O clima da região, segundo Espindola, Tosin e Paccola (1974), é do tipo mesotérmico, Cwa (subtropical úmido com estiagem no período de inverno). A precipitação média anual é de 1534 $\mathrm{mm}$, apresentando média para o mês mais chuvoso (janeiro) de $242 \mathrm{~mm}$, e de $38 \mathrm{~mm}$ para os meses mais secos (julho e agosto). A temperatura média anual é de $21^{\circ} \mathrm{C}$.

O solo da área é um Latossolo Vermelho Amarelo fase arenosa (EMBRAPA, 1999). Antes da realização do experimento avaliaram-se as características químicas do mesmo através de amostras obtidas a partir de 10 amostras simples, componentes de uma amostra composta retirada das áreas experimentais, na profundidade de $0-20 \mathrm{~cm}$, as quais foram analisadas conforme metodologia de Raij et al. (2001), que indicaram respectivamente, $\mathrm{pH}=5,5 ; \mathrm{MO}=9,4 \mathrm{~g} \mathrm{dm}^{-3} ; \mathrm{P}_{\text {resina }=} 26,2 \mathrm{mg} \mathrm{dm}^{-3}$; $\mathrm{H}+\mathrm{Al}=18,2 \mathrm{mmol}_{\mathrm{c}} \mathrm{dm}^{-3} ; \mathrm{K}=2,4 \mathrm{mmol}_{\mathrm{c}} \mathrm{dm}^{-3} ; \mathrm{Ca}=$ $18,4 \mathrm{mmol}_{\mathrm{c}} \mathrm{dm}^{-3} ; \mathrm{Mg}=5,8 \mathrm{mmol}_{\mathrm{c}} \mathrm{dm}^{-3} ; \mathrm{SB}=26,4$ $\mathrm{mmol}_{\mathrm{c}} \mathrm{dm}^{-3} ; \mathrm{CTC}=44,6 ; \mathrm{V}=60 \%$; $\mathrm{B}=0,15 \mathrm{mg} \mathrm{dm}^{-}$ 3; $\mathrm{Cu}=1,0 \mathrm{mg} \mathrm{dm}{ }^{-3} ; \mathrm{Fe}=24,6 \mathrm{mg} \mathrm{dm}{ }^{-3} ; \mathrm{Mn}=6,92$ $\mathrm{mg} \mathrm{dm}{ }^{-3}, \mathrm{Zn}=0,9 \mathrm{mg} \mathrm{dm}^{-3}$.

Foi realizada análise química do esterco de curral [ $\mathrm{N}=1,5 ; \mathrm{P}_{2} \mathrm{O}_{5}=1,5 ;$ Umidade $=14,3 ; \mathrm{MO}=41,0$; $\mathrm{C}=22,8 ; \mathrm{Ca}=1,20 ; \mathrm{Mg}=0,4 ; \mathrm{S}=0,3$ (\% na matéria seca); $\mathrm{Fe}=18650 ; \mathrm{Cu}=200 ; \mathrm{Mn}=364 ; \mathrm{Na}=2580$; $\mathrm{Zn}=386\left(\mathrm{mg} \mathrm{kg}^{-1}\right.$ de matéria seca) $\mathrm{pH}=7,8 ; \mathrm{C} / \mathrm{N}=$ 
16/1] antes da incorporação ao solo e verificou-se o teor de nitrogênio do esterco. A concentração de $\mathrm{N}$ da uréia, no cultivo com adubação mineral foi calibrado de acordo com o $\mathrm{N}$ do esterco de curral para manter a equivalência. Logo, a quantidade de $\mathrm{N}$ do esterco de curral e da uréia foi a mesma.

Para o fornecimento de água no experimento foi utilizado um sistema de irrigação por micro aspersão. Durante todo o ciclo, a irrigação foi realizada duas vezes ao dia, principalmente após o transplante.

O delineamento experimental utilizado foi em blocos casualizados em esquema fatorial $(2 \mathrm{x}$ 6), com quatro repetições, sendo duas fontes de adubação (esterco de curral e uréia) e seis doses de nitrogênio $\left(0,30,60,90,120,150 \mathrm{~g} \mathrm{~m}^{-2}\right.$ de uréia), aplicadas parceladas em duas vezes (no plantio e em cobertura) e as doses de adubação orgânica $(0,2,4$, 6,8 e $10 \mathrm{~kg} \mathrm{~m}^{-2}$ de esterco de curral), aplicadas no plantio.

A semeadura foi realizada em janeiro de 2008, em bandejas de poliestireno expandido de 128 células, contendo o substrato comercial Plantmax ${ }^{\circledR}$. Em cada célula foram colocadas cinco sementes de Jambu cv. Jambuarana. A emergência ocorreu aos sete dias, sendo realizado o desbaste deixando uma plântula por célula.

O transplante foi realizado aos 40 dias após a semeadura, manualmente, quando as mudas apresentavam-se com seis folhas, em quatro canteiros de $6 \mathrm{~m}^{-2}$, colocando-se 18 plantas por linha, sendo que cada canteiro constou de cinco linhas. $\mathrm{O}$ espaçamento utilizado foi de $20 \times 25 \mathrm{~cm}$. As capinas foram realizadas a cada dez dias, desde o início da instalação da cultura.

A adubação de cobertura foi feita aos 30 dias após o transplante para o cultivo mineral nas doses de $15,30,45,60,75 \mathrm{~g} \mathrm{~m}^{-2}$ de uréia, correspondendo a $50 \%$, uma vez que no plantio utilizou-se só 50\% da uréia nos tratamentos. Foram utilizados também $0,5 \mathrm{~kg} \mathrm{~m} \mathrm{~m}^{-2}$ de um fertilizante orgânico (biomix), recomendado pela legislação para produção orgânica de hortaliças. Esse fertilizante foi aplicado na adubação mineral e orgânica, e 15 dias depois foram aplicados $30 \mathrm{~g} \mathrm{~m}^{-2}$ de torta de mamona, conforme recomendações técnicas, em aplicações semanais, tanto na adubação orgânica como na adubação mineral.

A colheita foi feita pela manhã, aos 90 dias após a semeadura, na abertura do botão floral. Os ramos foram cortados a sete $\mathrm{cm}$ do solo (CARDOSO; GARCIA, 1997).

Foram avaliadas as seguintes características: altura $(\mathrm{cm})$ que foi determinada com auxílio de uma trena, medindo-se a planta do colo até o ápice, em seis plantas por parcela, antes da colheita, massa de matéria fresca que foi determinada pela pesagem em balança digital, da parte aérea das plantas.

Logo após essas análises procedeu-se a lavagem desse material em água corrente e em água com detergente, passando em seguida por duplo enxágüe em água deionizada para retirada de impurezas e as plantas foram acondicionadas em sacos de papel Kraft identificadas com os respectivos tratamentos e submetidas em estufa de circulação forçada de ar $\left(60^{\circ} \mathrm{C}\right)$ por 48 horas, até massa constante. Depois da retirada desse material da estufa determinouse a massa de matéria seca em balança digital. Em seguida realizou-se o cálculo de acúmulo de nutrientes realizado através do produto da massa seca e o teor de nutrientes e a produtividade calculada através da massa de matéria fresca pelo número de plantas por metro quadrado.

Analise de resíduos de agrotóxicos foram realizadas no Centro de Assistência Toxicológica (CEATOX)/IB/(UNESP). Essas análises foram realizadas com o proposito de enfatizar a não utilização de inseticidas durante o cultivo da planta.

Todos os dados obtidos foram analisados estatisticamente através da análise de variância, com teste F. A análise de regressão foi feita quando o fator dose de uréia e esterco de curral teve significância e no fator fonte aplicou-se o teste de Tukey (1\%) para a comparação de médias. Na 
interação entre doses e fonte, o efeito das doses foi estudado para cada fonte de cultivo. Estabeleceuse o coeficiente de correlação de Pearson ${ }^{\circledR}$, entre todas as características analisadas, onde as variáveis com coeficientes de correlação positiva e valores abaixo de 0,050 P tendem a aumentar junto. Para os resultados com coeficientes de correlação negativa e valores abaixo de 0,050 P, uma variável tende a diminuir, enquanto a outra diminue. Para resultados com valores $\mathrm{P}$ superiores a 0,050 , não há nenhuma relação significativa entre as duas variáveis. As análises foram feitas no "software" SISVAR (FERREIRA, 2000).

\section{Resultados e Discussão}

Houve efeito significativo da interação das doses e adubação, sendo que o uso de $120 \mathrm{~g} \mathrm{~kg}^{-1}$ de uréia induziu maior altura das plantas na adubação mineral (média de $43 \mathrm{~cm}$ ) resultado dentro do citado por Lorenzi e Matos (2002) que preconizam que o jambu atinge 30 a $40 \mathrm{~cm}$ de altura. Na adubação orgânica a maior média foi de $25,62 \mathrm{~cm}$ de altura para dose de $8 \mathrm{~kg} \mathrm{~m}^{-2}$ de esterco de curral (Tabela 1). Borges, Guerreiro e Fernandes (2010) trabalhando com plantas de jambu obtiveram média de $24,8 \mathrm{~cm}$ de altura, valor abaixo do encontrado nesse trabalho nas duas adubações utilizada. Como o nitrogênio esta relacionado com desenvolvimento, crescimento e diferenciação celular, isso evidencia essa interação na altura das plantas de jambu. Esse resultado tornase importante sob o ponto de vista de um provável monitoramento da absorção e do acúmulo dos nutrientes durante todo o ciclo da cultura.

$\mathrm{Na}$ adubação mineral a média de massa fresca da folha foi de $66,77 \mathrm{~g}$. Sendo essa média abaixo das médias obtidas por Borges, Guerreiro e Fernandes (2010), que foram de 125,6 g a máxima e a mínima de 105,6 g dependendo do solo de da dose de silício aplicado nas plantas de jambu, cultivadas em estufa de temperatura controlada. Esses mesmos autores também encontraram média mínima de massa seca de folha de $15,4 \mathrm{~g}$, e máxima de $18,8 \mathrm{~g}$, sendo essas médias acima das observadas neste trabalho, que foi de 10,40g para adubação mineral e 3,73g para a adubação orgânica. Isso pode ser justificado pela diferença de ambiente que ambos os trabalhos foram realizados. Uma vez que essa pesquisa foi desenvolvida em ambiente, tendo assim os fatores ambientais interferindo na absorção de nutrientes, como também uma maior transpiração das plantas, conseqüentemente menor quantidade de água na planta o que possivelmente poder ter acarretado na baixa quantidade de matéria seca e baixa quantidade de matéria fresca deste trabalho.

Para produtividade das plantas de jambu, não foi observado efeito significativo da interação tipos de adubação e doses de nitrogênio. Porém ocorreu efeito isolado do fator tipo de adubação, onde a adubação mineral apresentou maior produtividade em relação à adubação orgânica. A dose de $90 \mathrm{~g} \mathrm{~m}^{-2}$ de uréia proporcionou maior produtividade $\left(4,40 \mathrm{~kg} \mathrm{~m}^{-2}\right)$ (Tabela 1). Demonstrando assim que uma adubação com uréia provavelmente propiciará para o cultivo de plantas de jambu um maior desenvolvimento, em razão do efeito do $\mathrm{N}$ em plantio. $\mathrm{Na}$ adubação orgânica a dose de $4 \mathrm{~kg} \mathrm{~m}^{-2}$ de esterco de curral, proporcionou produtividade de $2,78 \mathrm{~kg} \mathrm{~m}^{-2}$ (Tabela 1). Com esses resultados observa-se que uma adubação de plantio com $4 \mathrm{~kg} \mathrm{~m}^{-2}$ de esterco de curral e aplicação de uréia em cobertura favorecerá uma excelente produtividade de plantas de jambu. 
Tabela 1. Altura, massa fresca, massa seca em folhas de jambu (Spilanthes oleracea cv. Jambuarana) e produtividade, cultivado sob adubação orgânica e mineral.

\begin{tabular}{|c|c|c|c|c|c|}
\hline \multirow{2}{*}{ Adubações } & \multirow{2}{*}{ Doses } & \multirow{2}{*}{ Altura } & \multicolumn{2}{|c|}{ Folha } & \multirow[b]{2}{*}{ Produtividade } \\
\hline & & & MF & MS & \\
\hline \multirow{7}{*}{ Orgânica } & $\mathrm{kg} \mathrm{m}^{-2}$ & $(\mathrm{~cm})$ & (g) & (g) & $\mathrm{kg} \mathrm{m}^{-2}$ \\
\hline & test & 19,17 & 60,11 & 3,15 & 2,22 \\
\hline & 2 & 20,04 & 63,38 & 4,19 & 2,35 \\
\hline & 4 & 21,25 & 69,50 & 4,43 & 2,78 \\
\hline & 6 & 23,37 & 63,46 & 3,75 & 2,43 \\
\hline & 8 & 23,58 & 58,91 & 3,72 & 2,33 \\
\hline & 10 & 25,62 & 58,68 & 3,11 & 2,29 \\
\hline \multirow{2}{*}{$\begin{array}{r}\text { Média } \\
\mathbf{R}^{2} \\
\end{array}$} & $\mathrm{~g} \mathrm{~m}^{-2}$ & $22,17 \mathrm{~b}$ & 62,34 a & 3,73 b & $2,40 \mathrm{~b}$ \\
\hline & & 0,97 & ------- & ----------- & ------------ \\
\hline \multirow{6}{*}{ Mineral } & test & 20,58 & 72,01 & 9,52 & 2,42 \\
\hline & 30 & 34,63 & 87,11 & 10,66 & 3,31 \\
\hline & 60 & 37,42 & 73,40 & 11,04 & 4,20 \\
\hline & 90 & 41,80 & 67,03 & 14,05 & 4,40 \\
\hline & 120 & 43,58 & 50,66 & 10,51 & 3,16 \\
\hline & 150 & 40,11 & 50,43 & 6,62 & 2,86 \\
\hline Média & & 36,34 a & 66,77 a & 10,40 a & 3,37 a \\
\hline Int. A*D & & $* *$ & NS & NS & NS \\
\hline $\mathbf{R}^{2}$ & & 0,96 & --------' & ----------- & ----------- \\
\hline CV (\%) & & 12,81 & 19,26 & 43,90 & 15,16 \\
\hline
\end{tabular}

Médias seguidas da mesma letra não diferem entre si pelo teste de Tukey, para as adubações (orgânica e mineral). NS: não significativo; **: significativo a 1\% de probabilidade, para interação adubação e doses.

Fonte: Elaboração dos autores.

Não houve interação significativa entre os fatores tipos de adubações e doses de nitrogênio para o acúmulo de $\mathrm{N}$ e $\mathrm{K}$ nas folhas das plantas de jambu (Tabela 2). Pelo resultado das médias, a adubação mineral foi melhor que a adubação orgânica para o acúmulo de $\mathrm{N}$ e K nas plantas de jambu.

$\mathrm{O}$ acúmulo de $\mathrm{N}$ nas folhas respondeu acentuadamente ao aumento das doses de esterco de curral e uréia como esperado. O maior acúmulo de $\mathrm{N}, 350,02 \mathrm{mg}$ planta $^{-1}$, foi obtido na dose de $10 \mathrm{~kg}$ $\mathrm{m}^{-2}$ de esterco de curral e 612,94 $\mathrm{mg}$ planta $^{-1}$ de $\mathrm{N}$, na dose de $90 \mathrm{~g} \mathrm{~m}^{-2}$ de uréia. $\mathrm{O}$ acúmulo encontrado correspondente a adubação orgânica, apresentada na Tabela 2 apresenta um acúmulo linear de $\mathrm{N}$ o que significa que a planta ainda poderia responder ao incremento desse nutriente. Nas hortaliças folhosas, o fornecimento de doses adequadas de nitrogênio favorece o desenvolvimento vegetativo, expande a área fotossinteticamente ativa e eleva seu potencial produtivo (FILGUEIRA, 2003). Isso justificaria a produtividade obtida neste trabalho, ressaltando que as aplicações de esterco de curral e uréia supriram a necessidade de $\mathrm{N}$ para o desenvolvimento das plantas de jambu. 
Tabela 2. Acúmulo de nitrogênio, fósforo e potássio em folhas de jambu (Spilanthes oleracea cv. Jambuarana), cultivado sob adubação orgânica e mineral.

\begin{tabular}{|c|c|c|c|c|}
\hline \multirow{2}{*}{ Adubações } & \multirow{2}{*}{ Doses } & \multicolumn{3}{|c|}{ Folha } \\
\hline & & $\mathrm{N}$ & $\mathrm{P}$ & $\mathrm{K}$ \\
\hline \multirow{7}{*}{ Orgânica } & $\mathrm{kg} \mathrm{m}^{-2}$ & & $\mathrm{mg}$ planta $^{-1}$ & \\
\hline & test & 292,18 & 60,25 & 565,67 \\
\hline & 2 & 298,71 & 65,91 & 592,23 \\
\hline & 4 & 307,44 & 65,99 & 624,08 \\
\hline & 6 & 310,21 & 68,32 & 689,28 \\
\hline & 8 & 336,25 & 70,09 & 601,90 \\
\hline & 10 & 350,02 & 72,15 & 581,06 \\
\hline Média & $\mathrm{g} \mathrm{m}^{-2}$ & 315,80 b & $67,11 \mathrm{a}$ & $609,03 \mathrm{~b}$ \\
\hline $\mathbf{R}^{2}$ & & --------- & 0,92 & ------------ \\
\hline \multirow{6}{*}{ Mineral } & test & 341,46 & 30,45 & 663,95 \\
\hline & 30 & 373,86 & 31,43 & 756,54 \\
\hline & 60 & 451,82 & 39,68 & 779,37 \\
\hline & 90 & 612,94 & 36,82 & 806,71 \\
\hline & 120 & 585,09 & 35,10 & 683,55 \\
\hline & 150 & 466,37 & 28,33 & 570,01 \\
\hline Média & & 471,92 a & 33,63 b & 710,02 a \\
\hline Int. A*D & & NS & $* *$ & NS \\
\hline $\mathbf{R}^{2}$ & & ---------- & $\mathbf{0 , 8 0}$ & ---------- \\
\hline CV (\%) & & 17,51 & 10,77 & 9,54 \\
\hline
\end{tabular}

Médias seguidas da mesma letra não diferem entre si pelo teste de Tukey, pra as adubações (orgânica e mineral). NS: não significativo; **: significativo a $1 \%$ de probabilidade, para interação adubação e doses.

Fonte: Elaboração dos autores.

Para o acúmulo de $\mathrm{P}\left(72,15 \mathrm{mg} \mathrm{planta}^{-1}\right)$ nas folhas de jambu, a adubação orgânica apresentou melhor resultado em relação a adubação mineral (uréia), onde a dose de $10 \mathrm{~kg} \mathrm{~m}^{-2}$ esterco de curral, proporcionou maior acúmulo(Tabela2). Isso podeser atribuído ao fato de o nitrogênio diminuir a absorção de P pelas plantas. Para Malavolta, Pimentel-Gomes e Alcarde (2002), os adubos orgânicos melhoram a estrutura e o arejamento do solo, retarda a fixação do fósforo e aumenta a capacidade de troca catiônica (CTC). Isso justificaria o maior acúmulo de $\mathrm{P}$ na adubação orgânica. Transparecendo assim que as concentrações de esterco de curral supririam a necessidade de $\mathrm{P}$ para o cultivo de planta de jambu, favorecendo tanto o acumulo de $\mathrm{P}$ para planta como também uma boa conservação do solo utilizado.

Para o acúmulo de $\mathrm{K}$ nas folhas a adubação mineral foi melhor que a orgânica, onde a dose de $90 \mathrm{~g} \mathrm{~m}^{-2}$ de uréia, proporcionou maior acúmulo
(806,71 mg planta $\left.{ }^{-1}\right)$ de $\mathrm{K}$ nas folhas de jambu. Provavelmente essa quantidade de uréia será suficiente para que o acúmulo de $\mathrm{K}$ nas folhas de jambu seja suficiente para o seu desenvolvimento. Segundo Carmello (1999), o nitrogênio é o macronutriente que está relacionado com os mais importantes processos bioquímicos e fisiológicos que ocorrem nas plantas, dentre os quais, a absorção iônica de outros nutrientes. Isso explica o maior acúmulo de $\mathrm{K}$ nas plantas de jambu na adubação mineral nessa pesquisa.

Ainda são escassas pesquisas relacionadas ao acúmulo de nutrientes para a espécie de jambu, o que dificulta a comparação de dados neste trabalho, no entanto os dados são coerentes, uma vez que a planta de jambu cultivada com adubação orgânica e mineral apresentou um bom desenvolvimento no campo. Todavia pelo fato de ser da mesma família que da alface (Asteraceae), observa-se que 
o acúmulo de nutrientes está acima das citadas normalmente para as cultivares de alface, por exemplo, a "Vera" e "Verônica".

Não foi detectada a presença de agrotóxicos fosforados e carbamatos em folhas de jambu cultivado sob adubação orgânica e mineral. No entanto, foi observada a presença de clorados em folhas de jambu cultivado sob adubação orgânica e mineral (Tabela 3).

Tabela 3. Resíduos de agrotóxico em folha de jambu (variedade jambuarana), cultivado sob adubação orgânica e mineral.

\begin{tabular}{llll}
\hline FOLHA & Clorados & Fosforados & Carbamatos \\
\hline Orgânica & POSITIVO & N.D & N.D \\
Mineral & POSITIVO & N.D & N.D \\
\hline
\end{tabular}

N.D $=$ Não Detectado

Fonte: Elaboração dos autores.

Stertz et al. (2005) realizando as análises de agrotóxicos em alface convencional, hidropônica e orgânica, constataram que as alfaces provenientes de sistema orgânico apresentamse isentas de agrotóxico, enquanto que a alface convencional mineral e hidropônica apresentaram respectivamente, $33,33 \%$ e $66,67 \%$ de suas amostras contaminadas. Resultado diferente foi encontrado neste trabalho, onde foi verificado resíduo de clorado nas folhas de jambu orgânico e mineral que pode ser atribuído a uma possível contaminação por cloro durante a desinfecção das plantas (resíduo). Porém, é importante que as pesquisas em relação a esse assunto avancem para que se tenha certeza do nível de contaminação ou ausência de agrotóxico nos alimentos.
Houve correlação significativa $(\mathrm{P}<0,01)$ da produtividade com as características de altura, massa fresca e massa seca na adubação orgânica e com todas as características analisas na adubação mineral (tabela 4). Para as características de altura, massa fresca e seca observa-se uma correlação significativa entre essas características tanto na adubação orgânica como na mineral, não houve correlação de produtividade com massa seca na adubação mineral e tampouco de $\mathrm{K}$ para as duas adubações utilizadas. Entretanto houve correlação significativa de K com massa fresca e seca nas duas adubações utilizadas para o cultivo de jambu. Beninni, Takahash e Neves (2005) trabalhando com alface hidropônica $\left(0,997^{* *}\right)$ e convencional $\left(0,847^{* *}\right)$ também encontraram correlação significativa entre o acumulo de K e a biomassa. 
Tabela 4. Correlação de Pearson ${ }^{\circledR}$ em folha de jambu (variedade jambuarana), para as características analisadas na adubação orgânica e mineral.

\begin{tabular}{|c|c|c|c|c|c|c|}
\hline Parâmetros & Altura & MF & MS & $\mathrm{N}$ & $\mathrm{P}$ & $\mathrm{K}$ \\
\hline \multicolumn{7}{|c|}{ Adubação Orgânica } \\
\hline Produtividade & $-0,060^{* *}$ & $0,922^{* *}$ & $0,787^{* *}$ & $-0,153^{\mathrm{ns}}$ & $0,034^{\mathrm{ns}}$ & $0,466^{\mathrm{ns}}$ \\
\hline Altura & & $-0,366^{* *}$ & $-0,310^{\mathrm{ns}}$ & $0,929^{* *}$ & $0,937^{* *}$ & $0,265^{\mathrm{ns}}$ \\
\hline MF & & & $0,835^{* *}$ & $-0,491^{* *}$ & $-0,252^{\mathrm{ns}}$ & $0,449^{* *}$ \\
\hline MS & & & & $-0,358^{* *}$ & $-0,044^{\mathrm{ns}}$ & $0,401^{* *}$ \\
\hline $\mathrm{N}$ & & & & & $0,898^{* *}$ & $-0,073^{\text {ns }}$ \\
\hline $\mathrm{P}$ & & & & & & $0,259^{\text {ns }}$ \\
\hline \multicolumn{7}{|c|}{ Adubação Mineral } \\
\hline Produtividade & $1,000^{* *}$ & $-0,483^{* *}$ & $0,205^{\text {ns }}$ & $0,826^{* *}$ & $0,382^{* *}$ & $0,144^{\mathrm{ns}}$ \\
\hline Altura & & $-0,483^{* *}$ & $0,205^{\text {ns }}$ & $0,826^{* *}$ & $0,382^{* *}$ & $0,144^{\mathrm{ns}}$ \\
\hline $\mathrm{MF}$ & & & $0,385^{* *}$ & $-0,580^{* *}$ & $0,139^{\text {ns }}$ & $0,624^{* *}$ \\
\hline MS & & & & $0,475^{* *}$ & $0,736^{* *}$ & $0,923^{* *}$ \\
\hline $\mathrm{N}$ & & & & & $0,492^{* *}$ & $0,238^{\mathrm{ns}}$ \\
\hline $\mathrm{P}$ & & & & & & $0,781^{* *}$ \\
\hline
\end{tabular}

** correlação foi significativa em nível de $1 \%(\mathrm{P}<0,01)$; Ns= Não significativo; $\mathrm{MF}=$ Massa fresca; MS= Massa seca.

Fonte: Elaboração dos autores.

O nitrogênio apresentou correlação significativa positiva com altura $\left(0,929^{* *}\right)$ e correlação negativa com massa fresca $\left(-0,491^{* *}\right)$ e massa seca $\left(-0,358^{* *}\right)$ na adubação orgânica e correlação significativa positiva com produtividade $\left(0,826^{* *}\right)$, altura $\left(0,826^{* *}\right)$, massa seca $\left(0,475^{* *}\right)$ e correlação negativa com massa fresca $\left(-0,580^{* *}\right)$ na adubação mineral. Beninni, Takahash e Neves (2005) obtiveram um uma correlação significativa entre o acumulo de $\mathrm{N}$ e parte aérea $\left(0,927^{* *}\right)$ na alface cultivada em sistema convencional.

Verifica-se uma correlação significativa entre $\mathrm{N}$ e P tanto na adubação orgânica $\left(0,898^{* *}\right)$ como na mineral $\left(0,492^{* *}\right)$. Desse modo, é indicada uma interação positiva entre N e P. Prado, Romualdo e Vale (2006) relataram que a maior absorção de $\mathrm{P}$ na presença de $\mathrm{N}$ seria causada pelo envolvimento de $\mathrm{N}$ nos processos de absorção e de transporte interno de P. Segundo Malavolta, Vitti e Oliveira (1997), absorção de P, nos vegetais, neste caso pelas folhas de jumbu è importante, pois $\mathrm{P}$ é parte integrante da ATP (adenosina 5-trifosfato); PEP (fosfoenolpiruvato), NADPH (nicotinamida adeninadinucleotídeo difosfato) e outros compostos bioquímicos que utilizam o fosfato como armazenamento de energia. Como vários processos metabólicos vitais dependem desse suprimento de energia, a nutrição adequada deste nutriente vai interferir diretamente sobre a síntese de proteínas e de ácidos nucleícos, e conseqüentemente influenciar o crescimento das plantas, o que pode justificar a correlação significativa de $\mathrm{P}$ com a altura nas duas adubações e massa seca, produtividade e $\mathrm{K}$ na adubação mineral.

\section{Conclusão}

Adubação mineral proporcionou maior biomassa, produtividade e acúmulo de $\mathrm{N}$ e $\mathrm{K}$ em relação à adubação orgânica utilizada. Preconizase a dose de $90 \mathrm{~g} \mathrm{~m}^{-2}$ de uréia como adequada para obtenção desses resultados. Contudo, a adubação orgânica favoreceu ao acúmulo de $\mathrm{P}$ nas plantas de jambu em relação à adubação mineral, sendo a dose de $10 \mathrm{~kg} \mathrm{~m}^{-2}$ de esterco de curral recomendada para conseguir esse resultado nas plantas de jambu.

Não foi detectada a presença de agrotóxicos fosforados e carbamatos em folhas de plantas jambu sob adubação orgânica e mineral. No entanto, foi observada a presença de clorados nas folhas nas duas adubações utilizada. 


\section{Agradecimentos}

À CAPES pela concessão da bolsa de mestrado à primeira autora.

\section{Referências}

AlBuRQUerQue, J. M. Plantas medicinais de uso popular. Brasília, DF: ABEAS/MEC, 1989. 96 p.

BENINNI, E. R. Y.; TAKAHASHI, H. W.; NEVES, C. S. V. J. Concentração e acúmulo de macronutrientes em alface cultivada em sistemas hidropônico e convencional. Semina: Ciências Agrárias, Londrina, v. 26, n. 3, p. 273282, 2005.

BORGES, L. S.; GUERRERO, A. C.; FERNANDES, D. M. Adubação foliar com silício no crescimento de plantas de jambu. Cultivando o Saber, Cascavel, v. 3, n. 1, p. 160-170, 2010.

CAMPANHOLA, C.; VALARINI, P. J. A agricultura orgânica e seu potencial para o pequeno agricultor. Cadernos de Ciência \& Tecnologia, Brasília, DF, v. 18, n. 13, p. 69-101, 2001.

CARDOSO, E. L.; OLIVEIRA. H. Sugestões de uso e manejo dos solos do assentamento Taquaral, CorumbáMS. Corumbá: Embrapa-Pantanal, 2002. 4 p. (Circular técnica, 35).

CARDOSO, M. O.; GARCIA, L. C. Jambu. In: CARDOSO, M. O. (Coord.). Hortaliças não convencionais da Amazônia. Manaus: EMBRAPA, CPAA, 1997. p. 133-140.

CARMELLO, Q. A. C. Curso de nutrição/fertirrigação localizada. Piracicaba: Departamento de Solos e Nutrição de Plantas, 1999. 59 p. Apostila.

EMPRESA BRASILEIRA DE PESQUISA AGROPECUÁRIA - EMBRAPA. Sistema brasileiro de classificação de solos. Brasília: EMBRAPA, 1999. 412 p.

ESPINDOLA, C. R.; TOSIN, W. A. C.; PACCOLA, A. A. Levantamento pedológico da Fazenda Experimental São Manuel. In: CONGRESSO BRASILEIRO DE CIÊNCIA DO SOLO, 14., Santa Maria. Anais... Santa Maria: Sociedade Brasileira de Ciência do Solo, 1974. p. 650-654.

FENOLL, J.; HELLIN, P.; LOPEZ, J.; GONZALEZ, A.; FLORES, R. Simplified multiresidue method for determination of pesticide residues in lettuce by gas chromatography with nitrogen-phosphorus detection. Analytical Bioanalytical Chemistry, Germany, v. 389, n. 2, p. 643-651, 2007.
FERREIRA, D. F. Análises estatísticas por meio do Sisvar para Windows versão 4.0. In: REUNIÃO ANUAL DA REGIÃO BRASILEIRA DA SOCIEDADE INTERNACIONAL DE BIOMETRIA, 45., 2000. São Carlos. Anais... São Carlos: UFSCar, 2000. p. 255-258.

FILGUEIRA, F. A. R. Novo manual de olericultura: agrotecnologia moderna na produção e comercialização de hortaliças. 2. ed. rev. e ampl. Viçosa: Ed. UFV, 2003. $412 \mathrm{p}$.

GOBO, A. B.; M. H. S.; KURZ, I. R.; PIZZUTTI, M. B.; ADIME, R. Z. Development and validation of methodology for the determination of residues of organophosphorus pesticides in tomatoes. Journal Brazilian Chemical Society, São Paulo, v. 15, n. 6, p. 945-950, 2004.

JACOBSON, M. The Structure of espilantol. Chemistry and Industry, London, v. 12, n. 2, p. 50-51, 1957.

JEYARATNAM, J. Organophosphorus compounds. Toxicology, Amsterdam, v. 91, n. 1, p. 15-27, 1994.

LORENZI, H.; MATOS, F. J. A. Plantas medicinais do Brasil: nativas e exóticas cultivadas. Nova Odessa, SP: Instituto Plantarum, 2002. 396 p.

MALAVOLTA, E.; PIMENTEL-GOMES, F; ALCARDE, L. C. Adubos e adubações. São Paulo: Nobel, 2002. 200 p.

MALAVOLTA, E.; VITTI, G. C.; OLIVEIRA, S. A. Avaliação do estado nutricional das plantas: princípios e aplicações. 2. ed. Piracicaba: Potafós, 1997. 319 p.

PAPADOPOULOS, I. Tendências da fertirrigação. In: FOLEGATTI, M. V. (Coord.). Fertirrigação: citrus, flores e hortaliças. Guaíba: Agropecuária, 1999. p. 11155.

PEIRIS, K. P. P.; SILVA, G. K. J.; RATNASOORIYA, W. D. Analgesic activity of water extract of Spilanthes acmella flowers on rats. Journal of Tropical Medicinal Plants, Malaysia, v. 2, n. 2, p. 201-204, 2001.

PRADO, R. M.; ROMUALDO, L. M.; VALE, D. W. Resposta da aveia preta à aplicação de fósforo sob duas doses de nitrogênio em condições de casa de vegetação. Acta Scientiarum, Maringá, v. 28, n. 4, p. 527-533, 2006.

PRAXEDES, M. G. Avaliação de características agronômicas da cenoura (Daucus carota L.) cultivada com biofertilizante. 2000. Trabalho de conclusão de curso (Graduação em Agronomia) - Centro de Ciências Agrárias. Universidade Federal da Paraíba, Areia.

RAIJ, B. van; ANDRADE, J. C.; CANTARELLA, H.; QUAGGIO, J. A. Análise química para avaliação da fertilidade de solos tropicais. Campinas: Instituto Agronômico, 2001. 285 p. 
RAMSEWAK, R. S.; ERICKSON, A. J.; NAIR, M. G. Bioactive $\mathrm{N}$-isobutylamides from the flower buds of Spilanthes acmella. Phytochemistry, Pergamon, v. 51, n. 6, p. 729-732, 1999.

RITTER, L. Report of a panel on the relationship between public exposure to pesticides and cancer. Câncer, Canada, v. 80, n. 10, p. 2019, 2033, 1997.

SANTOS, D. M. M. Nutrição mineral. Jaboticabal. UNESP. 2004. Disponível em: <http://www.fcav.unesp. br/download/deptos/biologia/durvalina/TEXTO-2.pdf. $>$. Acesso em: 06 ago.2008.
STERTZ, S. C.; FREITAS, R. J. S.; ROSA, M. I. S.; PENTEADO, P. T.P. S. Qualidade nutricional de alface (Lactuca sativa L.) mineral, orgânica e hidropônica. Visão Acadêmica, Curitiba, v. 6, n. 1, p. 1518-5192, jan./ jul. 2005.

VILLACHICA, H.; CARVALHO, J. E. U.; MÜLLER, C. H.; DIAZ, S. C.; ALMANZA, M. Frutales y hortalizas promissórios de la Amazônia. Lima: TCA; Secretaria Protempore, 1996. p. 110. 
